\title{
SURFACE QUALITY AND MACHINING TIME OPTIMIZATION BASED ON FEEDRATE CORRECTION FUNCTION OF TOOL TRAJECTORIES TYPES
}

\author{
Florea Dorel Anania, Andra Elena Pena, Miron Zapciu
}

Original scientific paper

Today, any CAM software offers some different tool trajectories strategies for milling free form geometries. In any finishing milling operation the most important objective is the surface quality. However, the CAM users must have the know-how to choose the tool trajectories according to geometry complexity, cutting tool geometry and its contact on the machined surface. The quality of the surface and machining time is influenced also by tool trajectories. Research results presented in this paper are focused on determination of a correction factor for cutting parameters based on tool trajectories type. To validate experimental correction factor, optimum feed rates are calculated for each type of trajectories based on surface quality and machining time analysis for inclined surfaces. The finishing procedures are made with a ball end milling tool.

Keywords: cutting parameters; machining time; milling; surface roughness; tool trajectory

Optimizacija kvalitete površine i vremena obrade na osnovu korekcije brzine posmaka putanje alata

Izvorni znanstveni članak Danas svaki CAM program nudi različite strategije putanje alata za glodanje geometrije slobodnih oblika. Svaka završna operacija glodanja usmjerena je kvaliteti površine. Ipak, korisnici CAM-a moraju znati kako odabrati putanju alata u skladu sa složenošću geometrije, geometrijom alata i njegovim dodirom s obrađivanom površinom. Na kvalitetu površine te vrijeme obrade djeluje i putanja alata. Rezultati ovog istraživanja usmjereni su određivanju faktora korekcije parametara rezanja na osnovu vrste putanje alata. U svrhu provjere eksperimentalnog faktora korekcije, izračunate su optimalne brzine posmaka za svaki tip putanje na temelju kvalitete površine i analize vremena obrade za kose površine. Završni postupci obrade načinjeni su alatom za glodanje s kuglastom glavom.

Ključne riječi: parametri rezanja glodanje; površinska hrapavost; putanja alata; vrijeme obrade

\section{Introduction}

In view of the increasing demands on the manufacturing accuracy as well as process efficiency and cost, the milling process is under constant development. By developing the milling process towards increased accuracy, there is a potential of increase in sustainability in the production system by eliminating process steps, e.g. grinding operations, after the milling process. The success of such development work is dependent on deep and detailed knowledge of the process behaviour [1].

With the recent increase in energy demand and constraints in carbon emissions, energy saving has become a priority for manufacturing industry. Energy savings up to $6 \div 40 \%$ can be obtained based on the optimum choice of cutting parameters, tools and optimum tool trajectories $[4,2]$

Current CAM systems provide good simulating procedures to view the overall surface geometry with swept volume procedures, but they do not consider the micro pattern pertaining to the cutting action of individual cutter flutes [5].

In uni-directional raster milling, a ball nose cutter will produce a concave groove across the part. The following cutter path will alter the geometry of this groove to leave a small cusp in the material. The size and shape of these cusps will categorize the roughness and appearance of the part [6]. The geometric properties of the surface will be dependent upon the cutter diameter, number of cutting flutes, the cutting speed, the step-over and the feedrate - factors that were studied widely in many researches. As we saw in [8] the cutting tool trajectory also influences the quality of the part. Many CAM systems have cutting simulations that show the progress of a cutter through the material, but they are unable to reproduce the actual geometric properties on the surface of the part, because they do not treat all the elements involved in the milling process $[10,8]$.

In this paper, some researches are presented regarding the influences of the tool trajectories type (which you can find in procedure of almost all CAM software) on the surface quality for a part with angled surfaces.

These researches are used for adjusting the machining parameters in order to obtain the same surface quality whatever the tool trajectories type.

\section{Materials and methods}

The general algorithm is based on roughness analysis for finishing procedures for a number of representative tool strategies which can be found almost in all CAM software. Our research is following the next 7 steps:

Step 1: Cutting regime calculus; Tool trajectories for finishing procedure set up: 9 strategies (6 Cimatron E, 3 WorkNC); Postprocessing $\rightarrow$ NC file

Step 2: New ball end tool setup; Part machining; Machining time measuring; Roughness measurement

Step 3: Correction coefficient calculus; Feedrate adjustment; CAM input new feederate; Post processing

Step 4: New ball end tool setup; Part machining; Machining time measuring; Roughness measurement

Step 5: Theoretical machining time calculus; Machining time comparative analysis; Roughness improvement comparative analysis; Roughness improvement versus machining time analysis

Step 6 Tool trajectories correction coefficient validation (time, roughness, etc)

Step 7 Machining parameters database; CAM software implementation; Standalone Cutting regime software 
As we can see one of the input parameters is the theoretical calculus of the cutting parameters based on the tool and the material that needs to be machined. Then, based on these results, the cusp height can be determined also by calculus and validated if the part respects the tolerances imposed. After that a CAM simulation is done and the resulting part is compared with the original one and surface deviation is measured. Then, to validate the results, the milling process takes place. In most of the cases the part obtained after machining is not identical with the one obtained from simulation because the CAM software does not take into account the cutting tool ware, the rigidity of the machine, the workpiece clamping etc. The next step is to optimize the process considering all the elements that could influence the surface quality [8, $10]$.

\section{Experimental tests}

The goal of the study is to identify and to quantify the influence of the tool trajectories types over the surface quality for a tilted planar surface (common for parts with cavities) in a 3D machining.

The material used was 6061 aluminum, one of the most common alloys of aluminum for general purpose use. This is a precipitation hardening aluminum alloy, containing magnesium and silicon as its major alloying elements. The main characteristics are: Density $2,7 \mathrm{~g} / \mathrm{cm}^{3}$; Modulus of elasticity $68,9 \mathrm{GPa}$; Poisson's ratio 0,33 ; Hardness Brinell 95; Hardness Rockwell 60; Tensile yield strength $276 \mathrm{MPa}$;

The part is a disc with $\varnothing 185 \mathrm{~mm}$. On this 10 identical external surfaces with the same angle $\left(165^{\circ}\right)$ were generated (Fig. 1).

Each surface has the same area of $717,805 \mathrm{~mm}^{2}$ with $0,2 \mathrm{~mm}$ offset after roughing procedures.

The cutting tests were made on a 3 axis machining center First MCV300 that has a maximum spindle speed of $8000 \mathrm{rpm}$, spindle power $7,5 \mathrm{~kW}$ and a maximum cutting federate of $10000 \mathrm{~mm} / \mathrm{min}$. On MCV 300 machining center the table has $X$ and $Y$ movement and the spindle is on $Z$ axis. The part was fixed directly on the machine table by using two brackets in order to assure maximum stiffness.

The cutting tool is a ball end mill with $10 \mathrm{~mm}$ diameter with 2 flutes (Fig. 1).

All cases investigated were carried out without coolant.

In order to evaluate the surface quality, a MitutoyoSurftest SJ210 instrument that has a measuring range (on $X$ axis) of 17,5 $\mathrm{mm}$ and a measuring speed of $0,25 \mathrm{~mm} / \mathrm{s}$, (Fig. 2) was used for the roughness measurement.

The machined part was fixed on a tripod mechanism with 3 degree of freedom in order to allow surface alignment with the measuring devices.

The MitutoyoSurftest SJ210 instrument was mounted on a machine table in order to assure the flatness.

Because the goal was to evaluate different milling strategies, two CAM softwares were used. The first 6 tool trajectories evaluated were from the software CimatronE and the last 3 are from WorkNC.
The NC files were generated with specific postprocessor for the used machine tool.

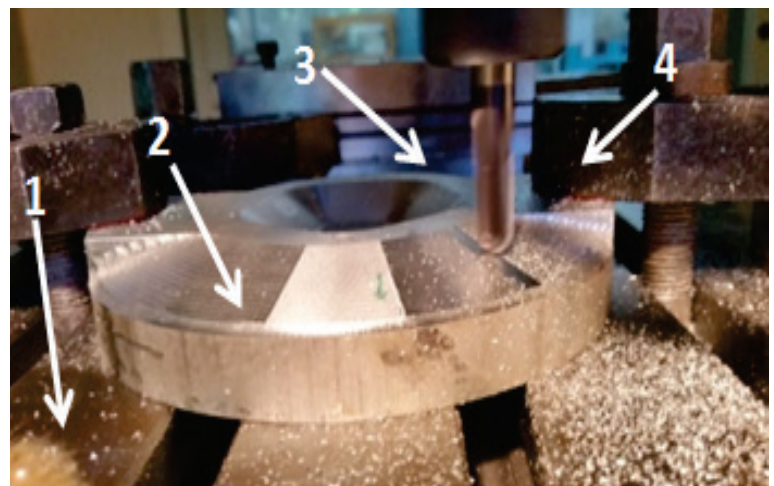

Figure 1 Experiments components: 1 - machine table; 2 - aluminum part; 3 - cutting tool; 4 - brackets.

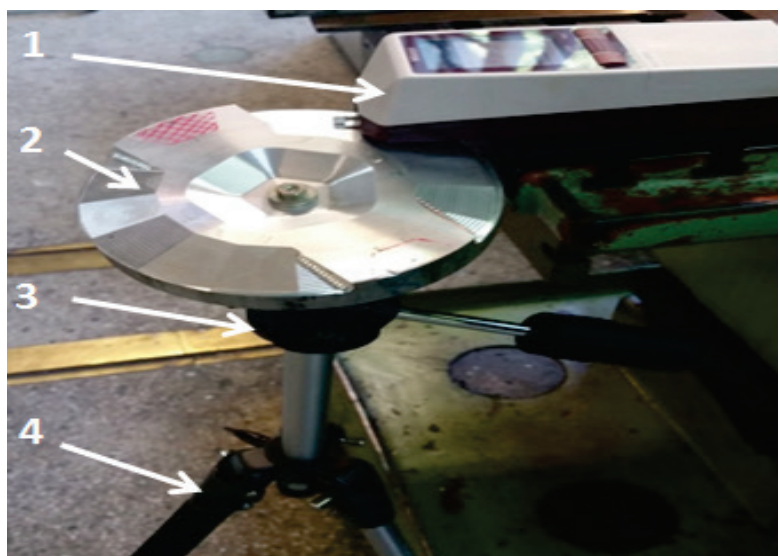

Figure 2 Roughness measurements: 1- MitutoyoSurftest; 2 machined part; 3 - alignment device with 3 degrees of freedom; 4 tripod.

These softwares are widely used in the industry and are between the most advanced CAM solutions.

The tool trajectory types are sketched in Figs. 3 and 4 by using a large radial step in order to be clear how the tool is moving over the surface. The tool trajectories' main characteristics are:

Type 1 - perpendicular to machine $Y$ axis bottom $\rightarrow$ top (Fig. 3, sketch 1)

Type 2 - perpendicular to machine $Y$ axis top $\rightarrow$ bottom (Fig. 3, sketch 2)

Type 3 - parallel top $\rightarrow$ bottom curves (Fig. 3, sketch 3 )

Type 4 - spiral from outside to inside (Fig. 3, sketch 4)

Type 5 - between curves top $\rightarrow$ bottom (Fig. 3, sketch 5)

Type 6 - between curves lateral (Fig. 3, schetch 6)

Type $7-3 \mathrm{D}$ drive curve finishing (Fig. 4, sketch 7)

Type 8-3D finishing (Fig. 4, sketch 8 )

Type 9 - Spiral/radial finishing (Fig. 4, sketch 9)

For the first and second case the particularity of the trajectory is that only $X$ and $Z$ machine axis is moving for interpolation.

For the third trajectories the tool has a linear movement and starts to cut from the top of the surface. The interpolation is made in $X Y$ plane and on $\mathrm{Z}$ is incremental.

The $4^{\text {th }}$ trajectory type is common for die surfaces. The tool is entering from outside of the surface and makes 
a spiral movement continuously up to the center of the surface.

The $5^{\text {th }}$ trajectory types are generated based on tow curves which are borders of the surface up and down. In this case the trajectories are the arcs of a circle.

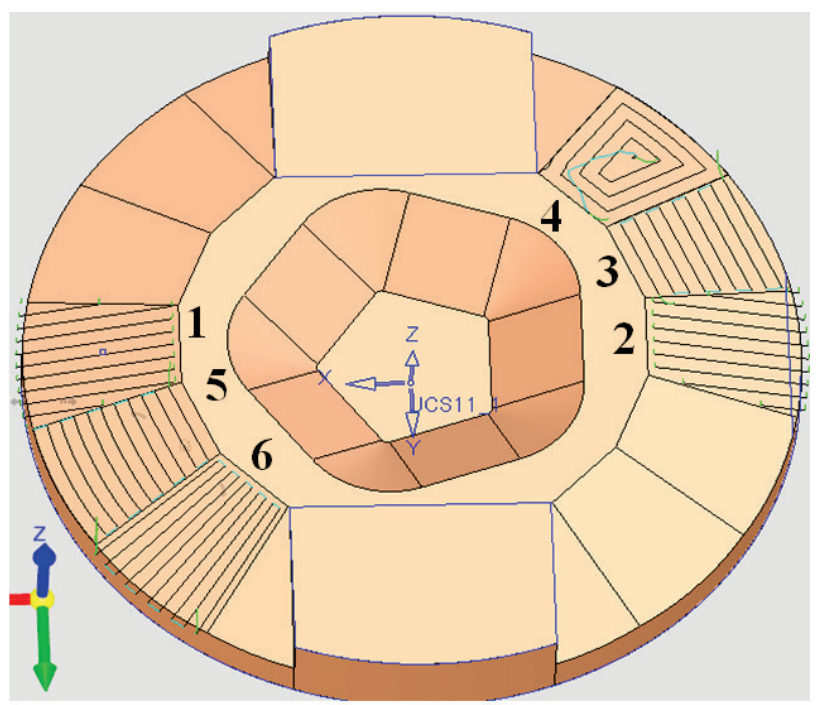

Figure 3 Cimatron trajectories type.

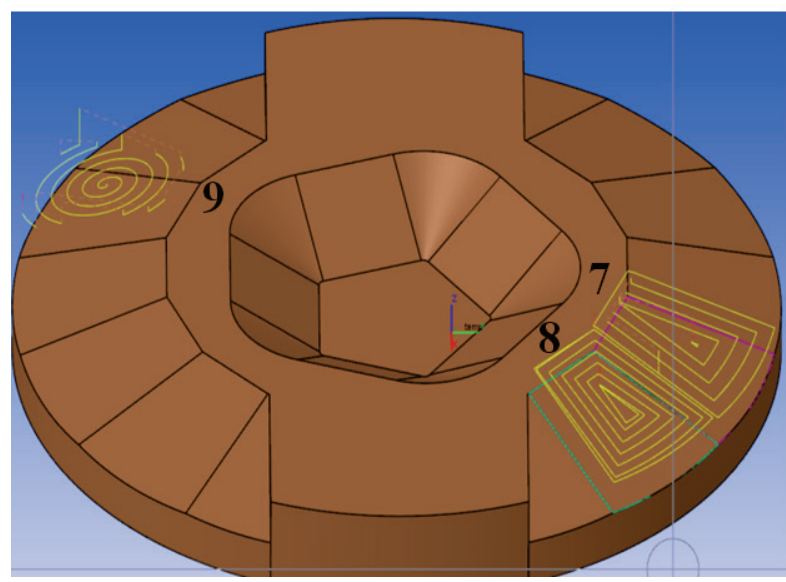

Figure 4 Work NC trajectories type

The main movement is made by interpolating $X$ and $Y$ machining axis.

The $6^{\text {th }}$ trajectory generating is based on two curves (lines) which are borders of the surface from lateral. In this case the movement is made by all 3 machine axes true 3D interpolation.

The $7^{\text {th }}$ and $8^{\text {th }}$ trajectories are similar. The tool follows the contour of the surface from outside to inside. In this case their interpolation also in $3 \mathrm{D}$ and in $2 \mathrm{D}$ depends on the tool position.

In the last case the tool is forced to move on true circular trajectories. The main advantage of this case is that the sharp corners over the trajectories are eliminated.

These tool trajectories are mostly used in machining in field like tooling, aerospace and automotive for milling operation in 3 axes NC.

We chose to study these trajectories because they are common for majority of CAM software for medium and advanced level.

The cutting regime parameters were calculated with the classic formulas with the value of the effective diameter of the tool. In the case of inclined surfaces machined with a ball end mill, the effective diameter in action is given by Eq. (1).

$d_{\mathrm{eff}}=d_{1} \cdot \sin \left(\alpha+\arccos \left(1-\frac{2 a_{\mathrm{p}}}{d_{1}}\right)\right)$.

And the maximum cutting speed of the end mill can be represented as:

$v_{\mathrm{c}}=\frac{\pi \cdot d_{\mathrm{eff}} \cdot n}{1000}$

$F=n \cdot z \cdot f_{\mathrm{z}}, \mathrm{mm} / \mathrm{min}$

$c h=\frac{d_{\mathrm{eff}}}{2}-\sqrt{\left(\frac{d_{\mathrm{eff}}}{2}\right)^{2}-\left(\frac{a_{\mathrm{e}}}{2 \cdot \cos \alpha}\right)^{2}}$.

The step over between the passes of the cutting tool generates the cusp height which gives the surface roughness. The cusp height can be determined by Eq. (4) .

This formula can be used to calculate the cusp hight and initial radial step for procedure parameters in CAM software. This formula is taking into account only the geometrical parameters of the tool and its relative position over surface [10].

The cutting regime used for all studied trajectories is: feedrate $F=1500 \mathrm{~mm} / \mathrm{min}$, main spindle speed $n=7000$ rpm, cutting speed $v_{\mathrm{c}}=202 \mathrm{~m} / \mathrm{min}$, and feed per flute $f_{\mathrm{z}}=$ $0,10 \mathrm{~mm} /$ tooth, effective diameter $d_{\text {eff }}=9,2 \mathrm{~mm}, a_{\mathrm{p}}=0,2$ $\mathrm{mm} ; a_{\mathrm{e}}=0,2 \mathrm{~mm}$.

A number of 18 experimental cutting tests were made in order to identify and quantify the influence of the tool trajectories over the quality of the machined surfaces. The results were analyzed and used to calculate the optimal machining parameters.

\section{Experimental results}

Not in all cases can we mill with the same cutting tool trajectory. So the goal is to achieve the same roughness no matter the strategy chosen. In order to obtain such a result, in this case we determined, based on the experimental results, a correction coefficient that applied to the feedrate will bring the surface roughness in the same value range.

For each surface roughness measurements were made in 3 points on 2 directions. For this measurement a global roughness for each surface was calculated as average of measurements.

To calculate the correction factor for machining parameters a constant reference value was established as minimum of $R a^{t}$ calculated (Eq. (5)), like we did in previous work [8].

The correction is calculated according to Eq. (6). The results are presented in Tab. 1

$$
\begin{aligned}
& R a^{\mathrm{ref}}=\min \left(R a^{t}\right), \text { where } t=1 \div 9 \\
& c_{R a}^{t}=\frac{R a^{\mathrm{ref}}}{R a^{t}},
\end{aligned}
$$


where: $t=1 \div 9$ - tool trajectories; $R a^{t}$ - reference roughness for each trajectory type; $R a^{\text {ref }}-$ constant reference value

Based on this correction factor a new cutting feed is calculated for each type of trajectories studied before.

$F_{\mathrm{c}}=n \cdot z \cdot f_{\mathrm{z}} \cdot c_{R a}^{t}, \mathrm{~mm} / \mathrm{min}$

The results are presented in Tab. 1. These new federates are introduced into cutting regime and the tests are made again.

Table 1 Feed adjusted to tool trajectories

\begin{tabular}{|c|c|c|}
\hline $\begin{array}{c}\text { Tool path } \\
\text { trajectory type }\end{array}$ & $\begin{array}{c}\text { Correction } \\
\text { coefficient }\end{array}$ & Recalculated feed \\
\hline Type 1 & 0,943 & 1415 \\
\hline Type 2 & 0,84 & 1261 \\
\hline Type 3 & 0,78 & 1163 \\
\hline Type 4 & Ref. & 1500 \\
\hline Type 5 & 0,55 & 829 \\
\hline Type 6 & 0,83 & 1240 \\
\hline Type 7 & 0,62 & 943 \\
\hline Type 8 & 0,55 & 833 \\
\hline Type 9 & 0,74 & 1087 \\
\hline
\end{tabular}

\section{Results and analysis}

For results analysis and interpretation, we had 3 approaches as follows:

1) Analysis of roughness based on the cutting test for corrected feedrate;

2) Machining time analysis based on corrected feedrate for toolpath type variation.

3) Machining time analysis versus roughness improvement.

\subsection{Roughness analysis}

The values of the roughness measurements after feed rate adjustment according to the value from Tab. 1 are presented in Fig. 5.

Table 2 Roughness variation

\begin{tabular}{|c|c|c|c|}
\hline \multirow{2}{*}{$\begin{array}{l}\text { Trajectory } \\
\text { type }\end{array}$} & \multicolumn{3}{|c|}{ Roughness variation } \\
\hline & $\begin{array}{l}\text { Original vs. } \\
\text { ref, } \%\end{array}$ & $\begin{array}{l}\text { Optimized vs. } \\
\text { ref, } \%\end{array}$ & $\begin{array}{l}\text { Optimized vs. } \\
\text { original, } \%\end{array}$ \\
\hline Type 1 & 6 & 0 & 6 \\
\hline Type 2 & 18 & 4 & 13 \\
\hline Type 3 & 30 & 8 & 20 \\
\hline Type 4 & Ref. & Ref. & Ref. \\
\hline Type 5 & 80 & 22 & 47 \\
\hline Type 6 & 20 & 0 & 20 \\
\hline Type 7 & 58 & 14 & 39 \\
\hline Type 8 & 80 & 24 & 45 \\
\hline Type 9 & 38 & 4 & 33 \\
\hline
\end{tabular}

It can be noticed that the roughness decreases around the reference value for all tool trajectories type.

After feedrate correction according to our calculus the roughness variation is under $20 \%$. For initial feedrate calculus based on classical formula the roughness variation is up to $80 \%$.
In Tab. 2 the variation of roughness is percentualy calculated based on reference value. From Tab. 2 can be noticed that the original roughness is $80 \%$ bigger than the reference roughness for toolpath Type 5 (between curves - top $\rightarrow$ bottom) and Type 8 (3D finishing) and after optimization is with $22 \%$ and respectively $24 \%$. The roughness obtained for optimized feedrate for these tool trajectories (Type 5 and Type 8 ) is by $47 \%$ and $45 \%$ better than the original one.

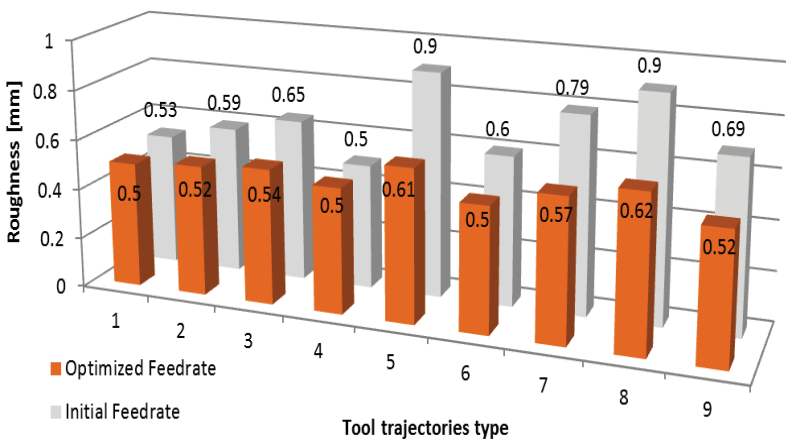

Figure 5 Surface quality -roughness analysis

\subsection{Machining time analysis}

By decreasing the feedrate the machining time is increasing. In order to check how machining time is affected by our calculus we calculated and measured the time for each tool trajectory type. In Fig. 6 are presented the results based on the fallowing:

Original time was measured for each tool trajectory type machining. It can be noticed that the time variation gives the function of the cutting length. We did not take into account the rapid time for positioning trajectories. Also for all strategies the lead-in and lead-out feed was the same and the tool engaged into material was made with the same radius. The difference is that for some tool trajectories there are a lot of lead-in, lead-out movements.

Theoretical time is calculated based on original time and correction coefficient presented in Tab. 1. The formula used was:

$T_{c}=\frac{T}{c_{R a}^{t}}, \min$

The calculated time is obtained by direct measurements on the machine for each toolpath where the recalculated feedrates were applied.

The difference between theoretical time and calculated time for the same trajectories is between 1 and $12 \%$. A reason for this could be the influence of the acceleration and deceleration of the machine.

If we analyze the original machining time and final time after feedrate correction variation between $2 \%$ and $80 \%$ can be observed. In Tab. 3 are presented the percentage variations between original time, calculated time and final time after feedrate optimization for each tool trajectory type. 


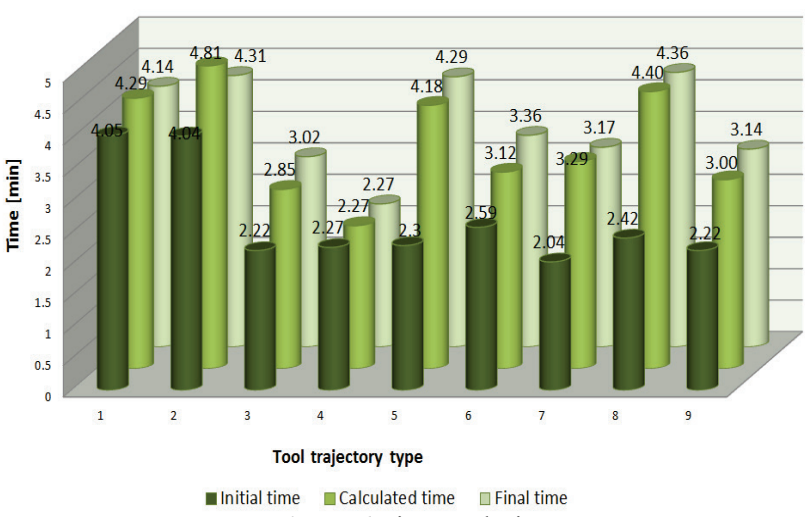

Figure 6 Time analysis

Table 3 Machining time variation

\begin{tabular}{|c|c|c|c|}
\hline \multirow{2}{*}{ No. } & \multirow{2}{*}{$\begin{array}{c}\text { Tool trajectory } \\
\text { type }\end{array}$} & $\begin{array}{c}|c| \\
\text { Tyitial vs. final, } \\
\%\end{array}$ & $\begin{array}{c}\text { Calculated vs. final, } \\
\%\end{array}$ \\
\hline 1 & Type 1 & 2 & 4 \\
\hline 2 & Type 2 & 7 & 12 \\
\hline 3 & Type 3 & 36 & -6 \\
\hline 4 & Type 4 & 0 & 0 \\
\hline 5 & Type 5 & 87 & -3 \\
\hline 6 & Type 6 & 30 & -7 \\
\hline 7 & Type 7 & 55 & 4 \\
\hline 8 & Type 8 & 80 & 1 \\
\hline 9 & Type 9 & 41 & -4 \\
\hline
\end{tabular}

\subsection{Roughness improvement vs. machining time}

The last analysis is made on assembly machining time- roughness improvement function of tool trajectories type.

The tool trajectories are taken into account by feedrate variation calculated based on correction coefficient (Eq. (6)). In Tab. 4 is presented variation of machining time and the roughness improvement obtained for each type of trajectories. In our calculus and analysis the references value is for the trajectory - spiral from outside to inside Type 4 where the best roughness has been obtained.

In this analysis it can be noticed that the optimum results from the point of view of machining time and roughness improvement are for tool trajectories Type 1, Type 2 and Type 6 . For tool trajectories Type 5 and Type 8 it can be observed that the machining time is increased by over $80 \%$ related to the initial time and the roughness improvement is around $30 \%$ (Fig. 7).

Table 4 Machining time - roughness analysis

\begin{tabular}{|c|c|c|c|}
\hline \multirow{2}{*}{ No. } & Trajectory type & Time variation & Roughness variation \\
\cline { 3 - 4 } & & $\begin{array}{c}\text { Initial vs. final, } \\
\%\end{array}$ & $\begin{array}{c}\text { Initial vs. optimized, } \\
\%\end{array}$ \\
\hline 1 & Type 1 & 2 & 5.7 \\
\hline 2 & Type 2 & 7 & 12 \\
\hline 3 & Type 3 & 36 & 17 \\
\hline 4 & Type 4 & Ref. & Ref. \\
\hline 5 & Type 5 & 87 & 32 \\
\hline 6 & Type 6 & 30 & 17 \\
\hline 7 & Type 7 & 55 & 28 \\
\hline 8 & Type 8 & 80 & 31 \\
\hline 9 & Type 9 & 41 & 25 \\
\hline
\end{tabular}

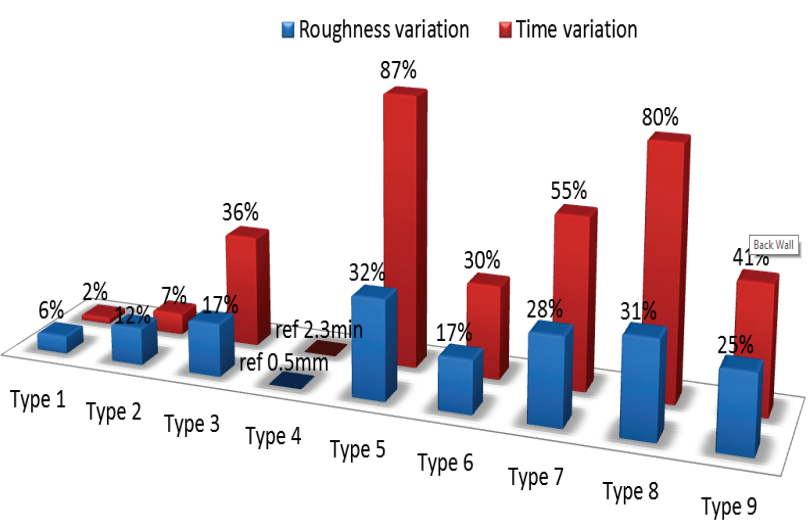

Figure 7 Roughness improvement vs. machining time

\section{Conclusion}

Until now the machining parameters were calculated based on standard formula from the point of view of milling on a classical machine tool. In those cases the operator is moving and the cutting regime is corrected in real time. By introducing $\mathrm{NC}$ machine tool and machining centre the cutting regime is done by $\mathrm{NC}$ programmer.

In the next step when the CAM software starts to be used the possibilities of $\mathrm{NC}$ programming become more flexible and more complex. For this the operator only makes the machine set-up. But even if the CAM software and the way of machining have evolved the cutting regime calculus remains the same. The results are different part qualities obtained by metal cutting for the same cutting regime.

The cutter path orientation is crucial in achieving desired machined surface and without considering the impact of cutting edge with unreformed chip in different path strategy with adequate consideration of the chip area variation, cutting forces, temperature and vibration analysis, the result can lead to cutter failure and therefore lead to unnecessary waste of time, cost and poor surface quality.

This work investigates the influences of the tool path strategy on the surface roughness and machining time. The right choice of the tool trajectories type can save valuable time and influences the surface quality.

Like a general conclusion our research is trying to fulfil a gap in metal cutting parameters calculus by taking into account a new parameter -tool trajectories type -the way the tool is moving over a surface.

Our research is from the point of view of surface roughness quality. In the first step we define and check an algorithm for feedrate correction for a plane surface for 5 tool trajectories type specific to plane machining [6].

The second step, presented in this paper, is on a more complex surface with a more complex tool and for 9 different tool trajectories specific to inclined surface. Tool trajectories were generated by two of the best and worldwide used types of CAM software (Cimatron E and WorkNC).

From our analysis a very good improvement can be observed of roughness after correction factor has been applied to the feedrate for all tool trajectories type. So no matter what tool trajectory is used by the engineer, by using our correction factor for feedrate the quality of the surface will be the same in a range of maximum $30 \%$. 
The time variation due to feedrate correction is the accuracy estimated by calculus too. From Tab. 2 and Fig. 7 it can be observed how machining time varies by feedrate modification. In this case we make theoretical calculus of the time and measurements on the machine for each of 18 experimental tests.

From the last analysis we recommend one of the Type 1, Type 2, Type 3, Type 6, Type 9 tool trajectories to be used with specific correction factor applied for roughness improvement. In these cases the best surface quality can be obtained but with low level of machining time costs. If it is impossible to use these strategies also tool trajectories Type 5, Type 7 and Type 8 can be used.

If the main criteria are machining times even for finishing the tool strategies Type 3, Type 4, Type 7 and Type 9 are recommended to be used.

The results obtained in this paper confirm that the proposed optimization method is a very useful tool for improving cutting parameters in finishing milling strategies.

Future work will be directed towards developing the software that implements the optimization method and offers suitable values for the machining parameters.

\section{Acknowledgements}

The work has been funded by the Sectoral Operational Programme Human Resources Development 2007-2013 of the Ministry of European Funds through the Financial Agreement POSDRU/159/1.5/S/132395.The work of Anania Dorel has been funded by the projet GEX no107/22.10.2016. funded by the University Politehnica from Bucharest.

\section{References}

[1] Modelling simulation and design in Machine tool field, chapter Computer aided manufacturing, Dorel Anania, Ed. Printech, ISBN 976-606-23-0290, Bucharest, 2014, pp. 257-305.

[2] Computer aided manufacturing, Cataling Amza, Dan Nitoi, Dorel Anania, Ed. Printech, ISBN 978-606-23-0399-0, Bucharest, 2015 pp. 212-252

[3] Andersson, C.; Andersson, M.; Stahl, J.-E. Experimental studies of cutting force variation in face milling. // International Journal of Machine Tools \& Manufacture. 51, (2011), pp. 67-76. https://doi.org/10.1016/j.jimachtools.2010.09.004

[4] Jihong, Y.; Lin L. Multi-objective optimization of milling parameters e the trade-offs between energy, production rate and cutting quality. // Journal of Cleaner Production. 52, (2013), pp. 462-471 https://doi.org/10.1016/j.jclepro.2013.02.030

[5] Prodan, D.; Bălan, E.; Bucuresteanu, A. Adjustment of vertical lathes rotational speed. // Proceedings in Manufacturing Systems. Ed. Academiei Romane, Bucuresti. 78, 1(2013), pp. 35-40.

[6] Newman, S. T.; Nassehi, A.; Imani-Asrai, R.; Dhokia, V. Energy efficient process planning for $\mathrm{CNC}$ machining. // CIRP Journal of Manufacturing Science and Technology. 5, 2(2012), pp. 127-136. DOI: 10.1016/j.cirpj.2012.03.007

[7] Pena, A. E.; Anania, F. D.; Zapciu, M. Research regarding software developing for machining parameters optimization calculus. // Applied Mechanics and Materials. 656, (2014), pp. 192-199.

https://doi.org/10.4028/www.scientific.net/AMM.656.192
[8] Liu, N.; Loftus, M.; Whitten, A. Surface finish visualisation in high speed, ball nose milling applications. // International Journal of Machine Tools and Manufacture. 45, 10(2005), pp. 1152-1161. https://doi.org/10.1016/j.ijmachtools.2004.12.007

[9] Pena, A. E.; Anania, F. D.; Zapciu, M. Research concerning optimum cutting parameters according with tool path strategy for finishing procedures. // ModTech International Conference, Proceedings of Modern Technologies in Industrial Engineering, Mamaia, Romania, 2015.

[10] Anania, F. D.; Stoica, M.; Petriceanu, C. Study in development of parametric algotithm for designing and machining of shaft features. // Proceedings of international conference on Innovative Technologies, IN-TECH 2015, Dubrovnik, 2015, pp. 411-414.

\section{Authors' addresses}

Florea Dorel Anania, PhD. Eng. Lecturer

University Politehnica of Bucharest, Machines and Production System Department Spl. Independentei, nr. 313, sector 6, RO-060042 Bucuresti, Romania dorel.anania@yahoo.com

\author{
Andra Elena Pena, PhD. Eng. Lecturer \\ University Politehnica of Bucharest, \\ Machines and Production System Department \\ Spl. Independentei, nr. 313, sector 6, \\ RO-060042 Bucuresti, Romania \\ andra.pena@yahoo.com

\section{Miron Zapciu, PhD. Eng. Professor} \\ University Politehnica of Bucharest, \\ Machines and Production System Department \\ Spl. Independentei, nr. 313, sector 6 , \\ RO-060042 Bucuresti, Romania \\ miron.zapciu@upb.ro
}

